\title{
Excisional Biopsy of Lymph Node
}

National Cancer Institute

\section{Source}

National Cancer Institute. Excisional Biopsy of Lymph Node. NCI Thesaurus. Code C51662.

A surgical procedure in which a single or multiple lymph nodes are removed for microscopic examination. 